is 'strategic'. Lane - and the rest of the science community - will either have to convince Congress that much basic research can comfortably wear that label or accept that research directions will have to be changed.

Supporters of science in Congress are sanguine about the outcome. "My feeling is that there's going to be no lessening of funding for basic research, but probably a little more guidance on which areas are critical for the nation - as we did before with defence-related science," says George Brown, chairman of the House Science, Space and Technology Committee.

But if funding for civil science is to grow — and 1993 has seen healthy budget increases at least at the NSF and the National Institute of Standards and Technology (NIST), the administration's chosen workhorse for technology transfer - defence research must continue to contract: there is nowhere else for the money to come from.

The ending of the Cold War would seem to point in this direction. Indeed, efforts are being made to ensure that concern for economic security delivers the same pay-off to the scientific community as did the previous concern for military security.

But the shift cannot be guaranteed, particularly with the recent nomination as Secretary of Defense of Admiral Bobby Inman, who has already expressed his independence from the administration in remarkably forthright terms, and is seen as the dark horse in the new "science cabinet". Inman has previously shown strong interest in research and high technology. A successful rearguard action by him to shore up the vast defence research budget could wreak havoc with Clinton's plans for expansion elsewhere.

\title{
Italy draws order out of chaos
}

Munich. Last month, Italy's Ministry of Research and Universities announced plans to scrap the country's much-criticized system of distributing research funds through small committees, and to introduce for the first time a formal peer-review process for almost all government-funded research.

This is the latest move by the ministry to develop tighter control over the quality of the research that it funds and align its procedures for allocating research funds more closely with those of other Western nations.

The new system will be introduced gradually beginning in 1994, when three per cent of all research grants will be allocated after peer review. It will be followed by a scheme under which research projects receive inter- national evaluation at defined intervals.

At the same time, discussions have begun between the ministry and Italian industry to identify long-term strategic research needs. The ministry has already decided to launch a strategic programme on robotics, once its budget for next year has been agreed. Also under consideration are programmes in environmental technologies, informatics and nanotechnology.

Much of the credit for bringing order into a reputedly chaotic ministry must go to the new minister of research, Umberto Colombo, who has been in office only since May. But he is not a politician, and therefore may be replaced after next spring's elections. If so, there are many in Italy who hope that the reforms he has started will be respected by his successor.

\section{Japan: Recession threatens shift to basic research}

Tokyo. While most countries around the world - including its immediate neighbours, South Korea and Taiwan - are promoting research aimed at developing new technologies, and cutting back on basic science, Japan, the pioneer of this strategy, is heading in the opposite direction.

But as the economic recession continues to bite and international competition becomes more fierce, Japan may find that it too comes under pressure to follow the worldwide trend in order to restore its economic growth. This will be a critical year for deciding which path it will follow in future.

Since the beginning of the 1980 s, government and industry in Japan have both accepted that they should support basic research, reacting in part to criticism from the West, and particularly the United States, of the country's perceived tendency to live off the fruits of Western science.

In the latter half of the decade, some of this talk was translated into action. Companies flush with cash began setting up basic research laboratories at home and overseas, the latter often in close association with Western universities.

Similarly, government agencies such as the Ministry of International Trade and Industry (MITI) launched a number of projects aimed at supporting basic research. A typical example is the International Human Frontier Science Program (HFSP), established in 1989 by MITI and the Science and Technology Agency (STA) to support international research on the brain and biological functions, with the bulk of the funding coming from Japan.

Public pronouncements and actions by the government still support this push for basic research. Last year, for example, the Ministry of Education, Science and Culture continued its drive for large increases in the budget for university research grants - still very small compared with some Western countries - with the aim of almost doubling the budget in a few years.

Similarly in October, MITI, in collaboration with industry, began a large project on long-term research on nanotechnology. Several US semiconductor manufacturers have joined the project because, they claim, it is difficult in the current economic climate to win support for such research from their own companies or government.

In line with this trend, a number of government-funded research organizations have carried out reforms and introduced external reviews to strengthen their ability in basic research. First off the mark was Tokyo University, which, after persuading the government to increase funding for buildings and graduate research, brought in a team of 